CASE REPORT

\title{
Thymus hyperplasia after resolution of hypercortisolism in ACTH-dependent Cushing's syndrome: the importance of thymic vein catheterization
}

\author{
Malebranche Berardo C Cunha Neto, Márcio Carlos Machado, Flávia Mesquita, Nina Rosa de Castro Musolino, \\ Andrea Cecília Toscanini, Gilberto Ochman, Valter Angelo S Cescato, Raul Marino Jr and \\ Manoel Jacobsen Teixeira \\ Neuroendocrine Unit, Division of Neurosurgery, Hospital das Clínicas, University of Sao Paulo School of Medicine, Rua Ovídio Pires de Campos \# 785 , \\ Cerqueira Cesar, 01060-970, Sao Paulo, SP, Brazil \\ (Correspondence should be addressed to M B C Cunha Neto; Email: malebrancheb@uol.com.br)
}

\begin{abstract}
Thymic hyperplasia has been described after the resolution of hypercortisolism from several etiologies, causing great diagnostic dilemmas. We describe a case where the catheterization of the thymic vein was essential for the differential diagnosis of a thymic enlargement in an adrenalectomized patient with ACTH-dependent Cushing's syndrome. The patient was a 48-year-old female with clinical and laboratorial data suggesting Cushing's disease. She underwent a transsphenoidal surgery with no tumor visualization and no remission of the syndrome. Histopathological studies disclosed a normal pituitary. She underwent a bilateral adrenalectomy and 8 months later a chest CT showed an increase of left thymic lobe, which was previously non-existent. After a negative ${ }^{111}$ In-pentetreotide scintigraphy, the patient underwent simultaneous and bilateral catheterism of the petrosus sinuses and catheterization of the thymic and inominate veins and no ACTH gradient was shown among the sites of collection. She did not undergo thoracotomy and a follow-up was established. During the evolution, there was a spontaneous regression of the thymic lesion 38 months after the diagnosis. The ACTH gradient during the catheterization of thymic vein was essential for the differential diagnosis of the thymic enlargement tumor after hypercortisolism resolution in ACTH-dependent Cushing's syndrome, especially in this case, where the ACTH source was occult, thus avoiding an invasive surgical procedure for a benign entity with spontaneous resolution.
\end{abstract}

European Journal of Endocrinology 154 807-811

\section{Introduction}

Corticotropic tumors represent $60-70 \%$ of all cases of endogenous hypercortisolism, and ectopic adrenocorticotropin (ACTH) secretion accounts for 10-20\% of ACTH-dependent Cushing's syndrome (1-3). Most of these ectopic tumors are located in the thoracic region (bronchial carcinoid tumor and small-cell lung carcinoma) $(1,4)$.

Thymic images are important for the differential diagnosis of ACTH-dependent Cushing's syndrome, since thymic tumors can represent the source of ACTH production. In a large series $(n=530)$ of ectopic tumors, thymic etiologies (carcinoid tumors, malignant thymoma and thymus hyperplasia) accounted for $11.2 \%$ of the cases (4).

Thymic hyperplasia has been described after the resolution of hypercortisolism in Cushing's syndrome, more commonly after adrenalectomy, but also after the resection of bronchial carcinoid tumors and corticotropic adenomas and following mitotane, ketoconazole and RU-486 use (5-7). The appearance of a thymic mass in a bilaterally adrenalectomized patient with ACTH-dependent Cushing's syndrome can create a dilemma regarding the differential diagnosis between thymic hyperplasia and ectopic tumor, especially in cases where the source of ACTH production remains occult.

We report a patient with post-adrenalectomy thymic enlargement who underwent simultaneous and bilateral catheterism of the petrosus sinuses and catheterization of the thymic and inominate veins in whom the absence of ACTH gradient among the sites and periphery was important in conveying the benign nature of the thymic enlargement and preventing the surgical investigation of the lesion. 


\section{Case report}

A 48-year-old female farmhand was admitted in May 1994. She had a 5-year history of secondary amenorrhea, muscle weakness, hirsutism, weight gain, facial fullness ("moon face"), lower member edema and headache. Arterial hypertension had been diagnosed one year before admission. She had a family history of arterial hypertension (mother) and diabetes mellitus (father). At the physical examination her weight was $43 \mathrm{~kg}$, body mass index: $21.5 \mathrm{~kg} / \mathrm{m}^{2}$, blood pressure: 150/100 $\mathrm{mmHg}$, cushingoid face features, supraclavicular fat pad, dorsocervical fat pad ("buffalo hump") and hirsutism were observed. Despite high normal serum cortisol levels, the diagnosis of ACTHdependent Cushing's syndrome was confirmed by high urinary cortisol, collected on three different occasions, cortisol non-suppression with low-dose $(1 \mathrm{mg})$ dexamethasone (serum cortisol $800 \mathrm{~h} 13 \mu \mathrm{g} / \mathrm{dl}$ ), loss of cortisol circadian rhythm of secretion (serum cortisol $1600 \mathrm{~h} 34 \mu \mathrm{g} / \mathrm{dl}$, normal value (NV): 4.3-14.5) and plasma ACTH $26.3 \mathrm{pg} / \mathrm{ml}$ (NV: 9-52). To achieve the differential diagnosis of ACTH-dependent Cushing's syndrome, cortisol suppression (36 to $2.9 \mu \mathrm{g} / \mathrm{dl}, 92 \%$ ) with high-dose dexamethasone $(8 \mathrm{mg} /$ classical $)$ and basal desmopressin test with positive cortisol $(16-28 \mu \mathrm{g} / \mathrm{dl}, \quad 75 \%)$ and ACTH response (26.3-67.8 pg/ml, 158\%) were observed; pituitary MRI disclosed no pituitary tumor and she had normal adrenal and thorax CT scans (normal lungs, no thymic enlargement and normal thyroid gland).

The patient underwent transsphenoidal surgery in November 1994 with no tumor visualization. A suspect pituitary fragment was removed during surgery, but the histological examination disclosed normal pituitary tissue. She maintained the hypercortisolism: serum cortisol $800 \mathrm{~h}: 21 \mu \mathrm{g} / \mathrm{dl}$ ( 5 days post surgery); desmopressin test with positive cortisol response (16-24 $\mu \mathrm{g} / \mathrm{dl}$, 11 days post surgery); elevated urinary cortisol (456 $\mu \mathrm{g} / 24 \mathrm{~h}, \mathrm{NV}$ : 30-300, 30 days post surgery) and ACTH $128 \mathrm{pg} / \mathrm{ml}$. A pituitary MRI, performed 4 months post surgery did not show any lesions. She underwent a bilateral adrenalectomy in July 1995 after ketoconazole use for 7 months. The anatomopathological analysis disclosed normal adrenal glands.

Eight months after the adrenalectomy (March 1996), a thorax CT disclosed an enlargement of the left thymic lobe, which was previously non-existent (Fig. 1). A thorax MRI confirmed a solid oval formation, 3.0 $\times$ $2.0 \times 1.5 \mathrm{~cm}$, with homogeneous textural pattern and a slight hypersignal on $\mathrm{T} 2$ weighted images. There was no thoracic ${ }^{111}$ In-pentetreotide captation, showing little likelihood of a neuroendocrine tumor. Due to the suspected thymic source of ACTH production, a bilateral catheterization of the inferior petrosus sinuses and inominate and thymic veins (in this order) was performed, after checking catheters positions, with no ACTH gradient $\geq 2$ among the periphery and petrosus sinuses and among the periphery and the thymic and inominate veins (Table 1). The test was performed without stimulation due to much patient discomfort during the procedure. Since there was no gradient, the follow-up was established, keeping the patient under close observation with no surgical intervention for thymic mass removal. In May 1999, there was a spontaneous regression of the lesion 38 months after the initial diagnosis. At the follow-up, the patient persists with high ACTH levels obtained before morning dose of cortisone acetate $25 \mathrm{mg}$ and fludrocortisone $100 \mu \mathrm{g} /$ day $(128-564 \mathrm{pg} / \mathrm{ml}$, NV: 9-52), and is currently performing annual serial imaging assessments of the pituitary, abdomen and thorax that have been negative for tumor lesions up to 2005 .

The patient signed an informed consent form and the study was approved by the Ethical and Research Committee of the Institution.

\section{Methods}

\section{Hormonal Assay}

Serum and urinary cortisol was measured by fluoroimmunoassay at an AutoDelfia System (Wallac Oy, Turku, Finland). Urinary cortisol was measured without extraction (total urinary cortisol). ACTH was measured by an immunoradiometric method (CIS bio International, Gif/Yvette, France).

\section{Discussion}

This woman has a prolonged course of ACTH production without localization of its source. This may suggest a pituitary origin for the tumor, but we cannot rule out ectopic, especially a carcinoid source of ACTH/CRH.

Thymic tumors are very significant in ACTHdependent Cushing's syndrome etiology. In a large series of 530 cases of ectopic tumors, thymic diseases accounted for $11.2 \%$ (carcinoid tumors, malignant thymoma and thymus hyperplasia) (4).

Thymic carcinoids vary greatly in size $(3-20 \mathrm{~cm})$, being, in general, smaller when they are ACTHproducing tumors $(5,8-12)$. Thorax CT is the initial examination tool in the assessment of thymic lesions, with possible image overlapping between normal thymic remnants and small carcinoid tumors (5). Besides tumor size, the lesion shape provides additional information for this differential diagnosis. The maintenance of a triangular shape (transversal cut) is suggestive of thymus hyperplasia $(5,13)$.

A review of thorax CT images in the diagnosis of Cushing's syndrome disclosed a prevalence of 33\% of thymic remnants tissues (nodules $>5 \mathrm{~mm}$ diameter or diffuse enlargement), especially in patients younger than 


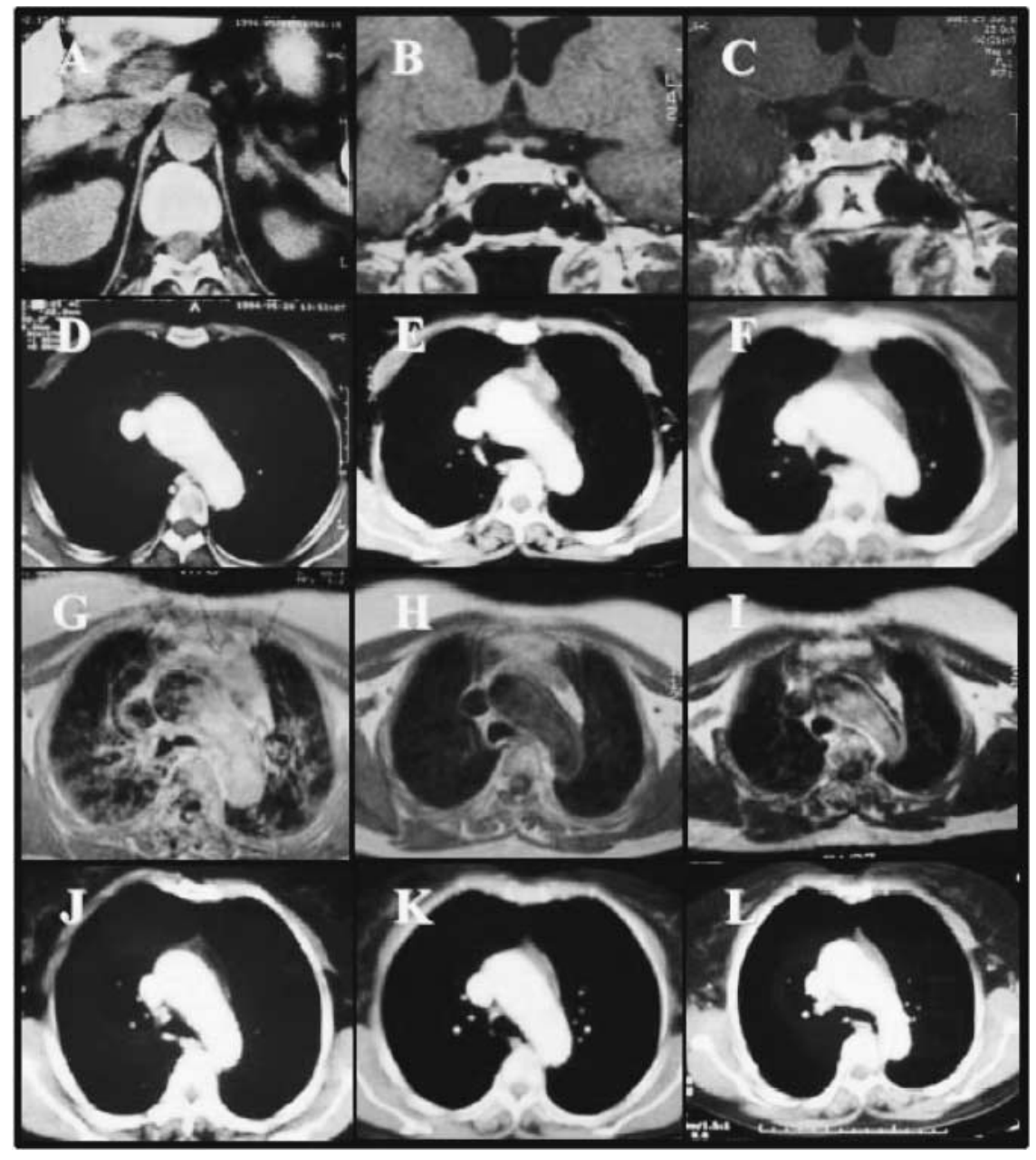

Figure 1 Ten years follow-up of CT/MRI images. A: Abdomen CT, 1994 (Initial); B: Pituitary MRI, 1994 (initial); C: Pituitary MRI, 2002; D: Thorax CT, 1994 (initial); E: Thorax CT, 1996 (thymus enlargement); F: Thorax CT, 1999 (resolution of thymus enlargement); G: Thorax MRI, 1996 (thymus enlargement); H: Thorax MRI, 1997; I: Thorax MRI, 1998; J: Thorax CT, 2000; K: Thorax CT, 2002; L: Thorax CT, 2004.
40 years, which did not correlate to cortisol levels. At this age range, the prevalence of thymic remnants varied from $53 \%(20-39$ years) to $100 \%$ ( $<20$ years). In patients older than 40 years, the prevalence was lower: $14 \%$. Therefore, the presence of thymic remnants in hypercortisolism is variable, being more common in younger patients. The finding of a larger thymic mass in patients older than 40 years is suggestive of neoplasia (5). Despite a 48-year-old patient, thorax CT showed a benign triangular shape of the thymus, as shown in Fig. 1.

Table 1 Catheterization of the thymic and inominate veins and simultaneous and bilateral catheterism of the inferior petrosus sinuses (ACTH). ACTH: NV: 9-52 pg/ml (standard international: 2-11 pmol/l; conversion factor:0.2202), IPS =inferior petrosal sinus, PER=periphery.

\begin{tabular}{lccc}
\hline Thymic vein & Inominate vein & PER & $\begin{array}{c}\text { Gradient: } \\
\text { thymic vein: PER }\end{array}$ \\
\hline 306 & 220 & 215 & $\begin{array}{c}1.4 \\
\text { Right IPS }\end{array}$ \\
146 & Left IPS & PER & Gradient: IPS: PER \\
& 259 & 260 & $<1$ \\
\hline
\end{tabular}

An ACTH-dependent Cushing's syndrome case of difficult management was reported, in which a previously non-existent thymic mass was shown 8 months after the resolution of hypercortisolism (bilateral adrenalectomy) in the presence of elevated plasma ACTH levels. The appearance of this lesion caused a diagnostic dilemma between ACTH-producing ectopic tumor and thymic hyperplasia secondary to bilateral adrenalectomy.

Twelve cases of thymic hyperplasia after resolution of hypercortisolism have been described, more commonly seen after an adrenalectomy, but also after the resection of bronchial carcinoid tumors and corticotrophic adenomas and following mitotane, ketoconazole and RU-486 use (5-7). Thymic hyperplasia has also been reported following other stressful situations: burns (14), chemotherapy (15-18) and cardiovascular surgery (19).

Tabarin et al. reported five cases of rebound thymic hyperplasia after resolution of Cushing's syndrome, calling them thymus pseudotumors. In four cases, the patients were submitted to thoracotomy, with histopathological analysis disclosing the diagnosis of thymus 
hyperplasia (7). Another study reported two patients who underwent thoracotomy due to thymic masses that appeared after childhood chemotherapy (15). These cases exemplify the diagnostic dilemma that appears, especially in ACTH-dependent Cushing's syndrome where the source of ACTH production remains occult, as in the reported case.

The natural history of thymic hyperplasia has not yet been defined, and may occur 3-4 weeks or several months after hypercortisolism resolution. Its average duration is variable, generally presenting spontaneous resolution and benign course $(6,7)$. It is possible that the stroma and epithelial tissues present a variable resistance to glucocorticoids, superior to the lymphoid component (5). There have been reports of thymic involution due to glucocorticoid use in children $(20,21)$, thymic atrophy induced by glucocorticoid therapy in the treatment of testicular neoplasia (16) and in vitro apoptosis of thymic cells in rats, secondary to excessive exposure to glucocorticoids (22).

There are no reports in the literature about thymic vein catheterism in the differential diagnosis between thymic hyperplasia after hypercortisolism resolution and thymic source of ACTH production. Doppman et al. reported the use of thymic vein catheterism in five patients with Cushing's syndrome due to ectopic ACTH production. All these patients showed thymic ACTH gradient and were submitted to thoracotomy. Two had thymic masses on thorax CT/MRI and confirmed thymic carcinoid tumors. One case presented ACTH-producing thymic hyperplasia with post-operative remission. Thymic source of ACTH was not confirmed in the two other patients and both had persistent Cushing's syndrome. The author concluded that the presence of a positive gradient at the thymus did not necessarily mean an ACTH-producing intra-thymic source and postulated that bronchial carcinoid tumors involving the central bronchial tree or mediastinal nodes may result in elevated levels of ACTH in thymic veins. This is probably because multiple small veins passing from the mediastinum into adjacent thymus tissue could provide an anatomic basis for the sampling results (23). On the other hand, we should remember that there was no ACTH gradient in our patients' catheterism and Doppman's data alerts us only for false positive results (40\%), so there were no false negatives in Doppman's paper. It must be remembered otherwise that un-stimulated bilateral inferior petrosal sinus catheter study involves a substantial proportion of false negative results.

Other diagnostic tools have been used to help localization of these neuroendocrine tumors, but were not conclusive in our case. Many carcinoid tumors, small-cell lung carcinomas and medullary thyroid carcinomas express a large number of somatostatin receptors. The ${ }^{111}$ In-pentetreotide scintigraphy has been used to locate occult lesions that cause ectopic ACTH Cushing's syndrome (1). A study that compared ${ }^{111}$ In-pentetreotide scintigraphy with CT and MRI did not show a higher sensibility of the scintigraphy regarding the diagnosis (1). Another series concluded that this image method does not present additional advantage to CT/MRI and showed several false positive results (24). However, a recent study showed two patients with ACTH-producing bronchial tumors in whom ${ }^{111}$ In-pentetreotide scintigraphy was the first imaging assessment technique to disclose the lesion, before the thorax CT and MRI (25). The role of this diagnostic tool in disclosing truly occult lesions remains to be clarified (1). The usefulness of positron emission tomography (PET) in the study of ACTH-producing occult tumors is not completely established (26). Thymus biopsy by videothoracoscopy can be an alternative, although it has not been reported in literature in the same context of our case, and there have been very few reports in other situations. There are reports of the successful use of videothoracoscopy in the excision of mediastinum lesions and thymectomy; it is, however, an invasive procedure that presents morbidity (post-surgical bleeding, for instance) $(27,28)$.

Recently, some cases of thymic hyperplasia were confirmed by cytopathological analysis after fine-needle aspirative biopsy of the thymus guided by ultrasound or $\mathrm{CT}$, which is a simpler and less invasive procedure $(29,30)$.

In the reported case, after a negative ${ }^{111}$ In-pentetreotide scintigraphy, the catheterism of the bilateral inferior petrosus sinuses, thymic and inominate veins was performed along with peripheral blood and no ACTH gradient was shown among the sites of collection. Although Doppman et al. reported limited accuracy of thymic ACTH gradient to define the real source of ACTH production (23), the absence of gradient in our case was important in choosing the conservative observational procedure. This decision was later confirmed as the best choice with the spontaneous involution of the lesion, thus avoiding the exploratory thoracotomy.

The use of glucocorticoid at pharmacological doses could, in theory, lead to an involution of the thymic hyperplasia but not of a neoplasia in this organ, perhaps constituting an interesting strategy for the differential diagnosis. We did not use this on our patient, since the procedure has never been described in the literature, making it difficult to decide which glucocorticoid should be used, as well as its dose and duration of treatment enough to warrant mass involution.

Thymic hyperplasia is therefore important in the context of ACTH-dependent Cushing's syndrome, and although it is rare, it must be recalled in cases after the resolution of hypercortisolism, as in our case, preventing an unnecessary surgical procedure, due to its nonmalignancy and spontaneous resolution. We conclude that negative ACTH gradient in thymic vein catheterism was important in our case, helping achieve a correct diagnosis, and we wait for other negative cases in the future literature to define this in a major number of patients. 


\section{References}

1 Newell-Price J, Trainer P, Besser M \& Grossman A. The diagnosis and differential diagnosis of Cushing's syndrome and pseudoCushing's states. Endocrine Reviews 199819 647-672.

2 Isidori AM, Kaltsas GA, Pozza C, Frajese V, Newell-Price J, Reznek RH, Jenkins PJ, Monson JP, Grossman AB \& Besser GM. The ectopic adrenocorticotropin syndrome: clinical features, diagnosis, management, and long-term follow-up. Journal of Clinical Endocrinology and Metabolism 200691 371-377.

3 Ilias I, Torpy DJ, Pacak K, Mullen N, Wesley RA \& Nieman LK. Cushing's syndrome due to ectopic corticotrophin secretion: twenty years' experience at the National Institutes of Health. Journal of Clinical Endocrinology and Metabolism 200590 4955-4962.

4 Beuschlein F \& Hammer GD. Ectopic pro-opiomelanocortin syndrome. Endocrinology and Metabolism Clinics of North America 200231 191-234.

5 Hanson JA, Sohaib SA, Newell-Price J, Islam N, Monson JP, Trainer PJ, Grossman A, Besser GM \& Reznek RH. Computed tomography appearance of the thymus and anterior mediastinum in active Cushing's syndrome. Journal of Clinical Endocrinology and Metabolism $1999 \mathbf{8 4} 602-605$.

6 Doppman JL, Oldfield EH, Chrousos GP, Nieman L, Udelsman R, Cutler GB \& Loriaux DL. Rebound thymic hyperplasia after treatment of Cushing's syndrome. American Journal of Roentgenology 1986147 1145-1147.

7 Tabarin A, Catargi B, Chanson P, Hieronimust S, Corcuff JB, Laurent F, Harter M, Drouillard J \& Roger P. Pseudo-tumours of the thymus after correction of hypercortisolism in patients with ectopic ACTH syndrome: a report of five cases. Clinical Endocrinology 199542 207-213.

8 Rosai J \& Higa E. Mediastinal endocrine neoplasm, of probable thymic origin, related to carcinoid tumour. Cancer $1972 \mathbf{2 9}$ 1061-1074.

9 Wick MR, Soctt RE, Li CY \& Carney JA. Carcinoid tumour of the thymus: a clinicopathologic report of seven cases with a review of the literature. Mayo Clinic Proceedings 198055 246-254.

10 Howlett TA, Drury PL, Perry L, Doniach I, Rees LH \& Besser GM. Diagnosis and management of ACTH-dependent Cushing's syndrome: comparison of the features in ectopic and pituitary ACTH production. Clinical Endocrinology $198624699-713$.

11 Wollensak G, Herbst EW, Beck A \& Shaefer HB. Primary thymic carcinoid with Cushing's syndrome. Vichows Archives A, Pathological Anatomy and Histopathology $1992 \mathbf{4 2 0} 191-195$.

12 Wang DY, Chang DB, Kuo SH, Yang PC, Lee YC, Hsu HC \& Luh KT. Carcinoid tumors of the thymus. Thorax $199449357-360$.

13 Moore AV, Korobkin M, Olanow W, Heaston DK, Ram DC, Dunnick NR \& Silverman PM. Age-related changes in the thymus gland: CT-pathologic correlation. American Journal of Roentgenology 1983 $141241-246$.

14 Gelfand DW, Goldman AS \& Law AJ. Thymic hyperplasia in children recovering from thermal burns. Journal of Trauma 1972 12 813-817.

15 Cohen M, Hill CA, Cangir A \& Sullivan MP. Thymic rebound after treatment of childhood tumors. American Journal of Roentgenology $1980135151-156$.

16 Hendrickx P \& Dohring W. Thymic atrophy and rebound enlargement following chemotherapy for testicular cancer. Acta Radiologica 198930 263-267.

17 Scheinpflug K, Schmitt J, Jentsch-Ullrich K, Roessner A \& Franke A. Thymic hyperplasia following successful treatment for nodularsclerosing Hodgkin's disease. Leukemia and Lymphoma $2003 \mathbf{4 4}$ 1615-1617.
18 Ascani S, Went P, Liberati AM, Piccaluga PP, Zinzani PL \& Pileri SA. Difficult diagnostic and therapeutic cases: CASE 1, True thymic hyperplasia in a patient treated for T-cell lymphoma. J Clin Oncol 200422 953-954.

19 Rizk G, Cuteo L \& Amplatz K. Rebound enlargement of the thymus after successful corrective surgery for transformation of the great vessels. American Journal of Roentgenology 1972 $116528-530$.

20 Caffey J \& Di Liberti C. Acute atrophy of the thymus induced by adrenocorticosteroids: observed roentgenographically in living human infants. American Journal of Roentgenology 196982 530-540.

21 Caffey J \& Sibley R. Results in overgrowth of the thymus after atrophy induced by oral administration of cortical steroids in human infants. Pediatrics 196026 762-770.

22 Cohen JJ. Glucocorticoid-induced apoptosis in the thymus. Seminars in Immunology 19924 363-369.

23 Doppman JL, Pass HI, Nieman LK, Miller DL, Chang R, Cutler GB, Chrousos GP, Jaffe GS \& Norton JA. Corticotropin-secreting carcinoid tumors of the thymus: diagnosis unreliability of thymic venous sampling. Radiology $199218471-74$.

24 Torpy DJ, Chen CC, Mullen N, Doppman JL, Carrasquillo JA, Chrousos GP \& Nieman LK. Lack of utility of (111)In-pentetreotide scintigraphy in localizing ectopic ACTH producing tumors: followup of 18 patients. Journal of Clinical Endocrinology and Metabolism $1999841186-1192$.

25 Tsagarakis S, Christoforaki M, Giannopoulou H, Rondogianni F, Housianakou I, Malagari C, Rontogianni D, Bellenis I \& Thalassinos N. A reappraisal of the utility of somatostatin receptor scintigraphy in patients with ectopic adrenocorticotropin Cushing's syndrome. Journal of Clinical Endocrinology and Metabolism $2003 \mathbf{8 8} 4754-4758$.

26 Arnaldi G, Angeli A, Atkinson AB, Bertagna X, Cavagnini F, Chrousos GP, Fava GA, Findling JW, Gaillard RC, Grossman AB, Kola B, Lacroix A, Mancini T, Mantero F, Newell-Price J, Niemen LK, Sonino N, Vance ML, Giustina A \& Boscaro M. Diagnosis and complications of Cushing's syndrome: a consensus statement. Journal of Clinical Endocrinology and Metabolism $2003 \mathbf{8 8}$ 5593-5602.

27 Roviaro G, Rebuffat C, Varoli F, Vergani C, Maciocco M \& Scalambra SM. Videothoracoscopic excision of mediastinal masses: indications and technique. Annals of Thoracic Surgery 199458 1679-1683.

28 Mantegazza R, Baggi F, Bernasconi P, Antozzi C, Confalonieri P, Novellino L, Spinelli L, Ferro MT, Beghi E \& Cornelio F. Videoassisted thoracoscopic extended thymectomy and extended transsternal thymectomy (T-3b) in non-thymomatous myasthenia gravis patients: remission after 6 years of follow-up. Journal of the Neurological Sciences 2003212 31-36.

29 Hoerl HD, Wojtowycz M, Gallagher HA \& Kurtycz DF. Cytologic diagnosis of true thymic hyperplasia by combined radiologic imaging and aspiration cytology: a case report including flow cytometric analysis. Diagnostic Cytopathology 200023 417-421.

30 Bangerter M, Behnisch W \& Griesshammer M. Mediastinal masses diagnosed as thymus hyperplasia by fine needle aspiration cytology. Acta Cytologica $2000 \mathbf{4 4} 743-747$.

Received 24 November 2005

Accepted 1 March 2006 